Editor,

I read an article published in the July 2016 issue of Sri Lankan Journal of Anaesthesiology, which studied the effects of infusion of phenylephrine at various doses in elective caesarean section patients under spinal anaesthesia. ${ }^{1}$ This article was informative.

I have some comments about the sentences written in the introduction section of that article. ${ }^{1}$

The sentence written in the introduction section, "Till recently, ephedrine was considered the vasopressor of choice for management of hypotension induced by spinal anaesthesia".2 does not convey the meaning properly because the reference cited was published in $1970 .{ }^{2}$ How can it be "Till recently"?

I also feel that reference no. 3 cited for another sentence in the introduction section, "Although a continuous infusion of prophylactic phenylephrine might be more effective in maintaining baseline systolic pressures, reports have expressed concerns over the large doses of phenylephrine required to maintain blood pressure resulting in reflex bradycardia" ${ }^{\prime \prime}$ is not specific for this sentence, because this sentence was written by Gupta $S$ in an editorial ${ }^{3}$ based on some other studies which he had mentioned in the next sentences.

Doherty A et al. ${ }^{4}$ had concluded in their study that there were no clinical benefits of administering phenylephrine as either infusion or bolus method. But, the sentence in the introduction section, "The optimal dosing regimen for administration of phenylephrine infusion is undetermined and current practice includes both phenylephrine infusion and intermittent bolus administration". ${ }^{6}$ written by Doherty A et al [Reference no.4 here] actually reflect their opinion only, which was prevailing at that time (2012). The same sentence is not applicable for 2016.

Hence, I feel that references cited should be specific to the context, time etc. Otherwise, it will not only be meaningless, but misleading the readers as well.

\section{MS Raghuraman}

Shri Sathya Sai Medical College and Research Institute, Ammapettai, Kancheepuram Dt., India.

\section{References}

1. Srinivasan NM, Gopalswamy NM. Optimal dose of phenylephrine infusion for management of maternal hypotension under spinal anaesthesia for caesarean delivery. Sri Lankan Journal of Anaesthesiology 2016; 24(2):64- 69

https://doi.org/10.4038/slja.v24i2.8146

2. James FM, Greiss FC. Kemp RA. An evaluation of vasopressor therapy for maternal hypotension during spinal anesthesia. Anesthesiology 1970;33:25-34.

https://doi.org/10.1097/00000542-19700700000010

3. Gupta S. Vasopressors and tight control of maternal blood pressure during caesarean delivery. A rocky alliance. J AnaesthesiolClinPharmacol 2013;29:1-3. https://doi.org/10.4103/0970-9185.105777 PMid:23495264 PMCid:PMC3590510

4. Doherty A, Ohashi Y, Downey K, Carvalho JCA. Phenylephrine infusion versus bolus regimens during cesarean delivery under spinal anesthesia: A double blind randomized clinical trial to assess hemodynamic changes. Anesth Analg 2012;115: 1343-5

https://doi.org/10.1213/ANE.0b013e31826ac3db PMid:23011562

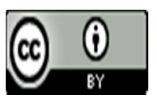

(C) 2017. Raghuraman. This is an Open Access article distributed under the terms of the Creative

Commons Attribution License (http: //creativecommons.org/licenses/by/4. 0), which permits unrestricted use, distribution, and reproduction in any medium, provided the original work is properly credited 